\title{
Imaginarios sociales e identidad de la cultura mexicana en los memes de la Copa del Mundial de la FIFA 2018
}

\author{
Social imaginaries and identity of Mexican culture \\ in the memes of the 2018 FIFA World Cup
}

\author{
Autor: \\ Jacob Bañuelos \\ "El mexicano es un ser que cuando se expresa se oculta; \\ sus palabras y gestos son casi siempre máscaras" (Paz, 1992, p. 67).
}

\section{Resumen}

Los memes se han convertido en una forma de expresión representativa de la cultura mediática digital, empleada para la representación de valores e imaginarios sociales. Como caso de estudio realizamos el análisis de los memes publicados en el marco de la actuación de la selección mexicana de fútbol en la Copa Mundial de FIFA-Rusia 2018, lo que permitió comprender los imaginarios sociales que construyen la identidad cultural mexicana en redes como Facebook, Instagram, Twitter y plataformas digitales como WhatsApp y Sitios Web Informativos. El estudio aplica una metodología etnográfica digital cualitativa, con enfoque sociocultural, para fenómenos en redes y plataformas digitales (Hine, 2005; Wouters y Beaulieu, 2009; Ardèvol y Gómez, 2012), lo permitió recuperar 600 memes en diversas comunidades, plataformas y redes sociales cercanas. Para su categorización y análisis empleamos los conceptos sobre imaginarios sociales de Cornelius Castoriadis (1997), identidad mexicana desde Ramos (1951), Paz (1992), Villoro (2018), Giddens (1997), Giménez (2000), Berger y Luckmann (2006), así como el abordaje de conceptos propios de las narrativas digitales como el mismo meme en Dawkins (1989), transmedia y multiplataforma, desde Jenkins (2008) y Scolari (2013). El estudio revela que los memes publicados en el contexto de este evento deportivo, a través de plataformas digitales y redes sociales, representan imaginarios sociales instituidos con valores que han prevalecido y se actualizan en la definición de la identidad cultural mexicana.

Palabras clave: Meme, Redes Sociales, Plataformas Digitales, Imaginarios Sociales, Identidad, México 


\section{Abstract}

Memes have become a form of expression representative of the digital media culture, used for the representation of social values and imaginaries. As a case study, we analyzed the memes published within the framework of the performance of the Mexican soccer team at the 2018 FIFA World Cup-Russia, which allowed us to understand the social imaginaries that build Mexican cultural identity in networks such as Facebook, Instagram, Twitter and digital platforms such as WhatsApp and Informative Websites. The study uses a qualitative digital ethnographic methodology, with a sociocultural approach, for phenomena in networks and digital platforms (Hine, 2005, Wouters and Beaulieu, 2009, Ardèvol and Gómez, 2012), which allowed to recover 600 memes in various communities, platforms and networks close social. For its categorization and analysis we used the concepts of social imaginaries of Cornelius Castoriadis (1997), Mexican identity from Ramos (1951), Paz (1992), Villoro (2018), Giddens (1997), Giménez (2000), Berger and Luckmann ( 2006), as well as the approach to concepts of digital narratives such as the meme in Dawkins (1989), transmedia and multiplatform, from Jenkins (2008) and Scolari (2013). The study reveals that the memes published in the context of this sporting event, through digital platforms and social networks, represent social imaginaries instituted with values that have prevailed and are updated in the definition of the Mexican cultural identity.

Keywords: Meme, Social Networks, Digital Platforms, Social Imaginaries, Identity, Mexico

\section{Introducción}

En el presente estudio analizamos los imaginarios sociales de la identidad mexicana en los memes publicados en torno a la actuación de la selección mexicana de fútbol en la Copa Mundial de la FIFA en Rusia 2018 (CMFR-2018). Memes generados y compartidos en diferentes plataformas digitales como redes sociales, portales informativos y servicios de mensajería instantánea. El análisis se realiza desde valores culturales de la sociedad mexicana, no es un análisis cuantitativo, estético, retórico o semiótico, sino sociocultural.

El estudio tiene como fin principal dar respuesta a la pregunta eje de esta investigación: ¿Qué imaginarios sociales construyeron la identidad cultural mexicana a través de los memes publicados en el contexto de la Copa Mundial de la FIFA en Rusia 2018?

Los memes se han convertido en un fenómeno mundial en redes sociales y plataformas de mensajería y la sociedad mexicana hace uso convulsivo de este recurso de expresión visual-textual ante cualquier evento o hecho socio-histórico o socio-cultural que incida en el imaginario colectivo. Los memes son, sin duda, una forma de expresión que representan o reflejan un imaginario social (Castoriadis, 1975) y una construcción que representa sus valores culturales identitarios, ideológicos, estéticos y morales.

Un imaginario social es una construcción socio histórica que abarca el conjunto de instituciones, normas y símbolos que comparte un determinado grupo social y, que pese a su carácter imaginado, opera en la realidad ofreciendo tanto oportunidades como restricciones para el accionar de los sujetos. De tal manera, un imaginario no es una ficción ni una falsedad, sino que se trata de una realidad que tiene consecuencias prácticas para la vida cotidiana de las personas (Castoriadis, 1997, p. 248, en Miranda, 2014, p. 7). 
Para Castoriadis: "Las significaciones imaginarias sociales crean un mundo propio para la sociedad considerada, son en realidad ese mundo: conforman la psique de los individuos. ...va parejo con la creación del impulso de la sociedad considerada (una intención global, por así decir) y un humor o Stimmung específico -un afecto o una nebulosa de afectos que embeben la totalidad de la vida social" (Castoriadis, 1997, p. 9).

Los memes entendidos como imaginarios sociales construyen, resignifican y desvían el sentido heredado históricamente, recreando lo que Castoriadis llama la lógica heredada (identitario-conjuntista) y el imaginario social, que son complementarios. La lógica heredada (identitario-conjuntista) es la herencia histórica determinada de valores, la cosmovisión, el sentido del orden, el lenguaje, los códigos, las matemáticas, la herencia de valores socioculturales y, por otra parte, el imaginario social que se inscribe en lo inconsciente, en lo indeterminado, en la imaginación.

\subsection{Lógica heredada y valores identitarios}

Para comprender la lógica heredada en el caso de México para el análisis de los memes publicados en el contexto de la Copa Mundial de la FIFA en Rusia 2018, recuperamos el pensamiento expresado en diversos ensayos de pensadores mexicanos como Samuel Ramos (1951) y Octavio Paz (1992) que revisan de manera detallada los valores identitarios de la cultura mexicana, básicamente resumidos en: sentimiento de inferioridad, machismo, sexismo, racismo, exaltación de la religión católica y auto-discriminación. Valores instituidos simbólicamente, heredados culturalmente y que vemos claramente reflejados en los imaginarios sociales expresados en la producción de memes en el contexto de este estudio.

El ensayo de Ramos (1951) El perfil del hombre y la cultura en México, se convierte en la primera obra post-revolucionaria que reflexiona sobre la identidad de los mexicanos, desde una perspectiva sociocultural y desde la psicología, convirtiéndose en puntal para las reflexiones posteriores. Ramos se basa en el sentimiento de inferioridad para emprender el análisis de la identidad y la cultura mexicana. "Sostengo que algunas expresiones del carácter mexicano son maneras de compensar un sentimiento inconsciente de inferioridad... Lo que afirmo es que cada mexicano se ha desvalorizado a sí mismo, cometiendo, de este modo, una injusticia a su persona" (Ramos, 1951, p. 10, en Magallón 2007, p. 19).

Paz por su parte, reconoce esta obra de Ramos como "el único punto de partida que tenemos para conocernos" (Paz, 1992, p. 67) aunque es crítico con sus conclusiones. Paz elabora posteriormente un ensayo analítico contundente sobre la identidad del mexicano, El laberinto de la soledad publicado en 1950, en donde explora los valores socioculturales que dictan la identidad al mexicano (sentimiento de inferioridad, simulación, falsedad, machismo, sexismo, racismo, religiosidad, muerte), como heredero de un proceso de Conquista por parte de España y receptáculo de procesos de Independencia y Revolución mexicanas, inscrito en el México moderno.

Algunas ideas centrales de Paz apuntalan la reflexión sobre los imaginarios sociales instituidos que encontramos en esta investigación, "Viejo o adolescente, criollo o mestizo, general, obrero o licenciado, el mexicano se me aparece como un ser que se encierra y se preserva: máscara el rostro y máscara la sonrisa" (Paz, 1992, p. 10). 
De acuerdo con Paz "... los mexicanos consideran a la mujer como un instrumento, ya de los deseos del hombre, ya de los fines que le asignan la ley, la sociedad o la moral. (...) Prostituta, diosa, gran señora, amante, la mujer transmite o conserva, pero no crea, los valores y energías que le confían la naturaleza o la sociedad" (Paz, 1995, pp. 12-13).

Finalmente, como parte del mosaico identitario que analiza Paz, la figura de la Malinche como la mujer que se entrega al conquistador Hernán Cortés, considerada una traidora en la cultura mexicana: "Ella encarna lo abierto, lo chingado, frente a nuestros indios, estoicos, impasibles y cerrados" (Paz, 1995, p. 35). La Maliche encarna el amor, la entrega y admiración por lo extranjero, otro valor socicultural mexicano reducido a la expresión "eres un malinchista": "Los malinchistas son los partidarios de que México se abra al exterior: los verdaderos hijos de la Malinche, que es la Chingada en persona. De nuevo aparece lo cerrado por oposición a lo abierto" (Paz, 1992, p. 36).

Además de la reflexión y análisis de la identidad mexicana en Ramos (1951) y Paz (1992), encontramos importantes estudios sobre la construcción social y colectiva de la identidad en autores relevantes como Giddens, A. (1997), Wolton (1999), Giménez (2000), Mandoki (2006), Berger, P. L. y Luckmann, T. (2006). Estos autores conducen la reflexión sobre la construcción de la identidad como un proceso dinámico en constante transformación, poniendo el acento en la estructuración simbólica de la misma, mediante interacciones sociales y referentes colectivos. Estas interacciones y referentes colectivos se forjan a través de instituciones socioculturales como la familia, la religión, la escuela, el arte, la moral social y los medios de comunicación.

\subsection{Memes}

La teoría y estudios sobre el meme es amplia, diversa y se expande progresivamente; encontramos básicamente tres enfoques de investigación, no excluyentes y siempre complementarios, desde una dimensión intangible o como artefacto, que abordan definiciones, análisis, humor, identidad y comportamiento en las redes sociales desde perspectivas informacionales, comunicacionales y socioculturales, a grandes rasgos:

1. Estudios que trabajan sobre definiciones, tipologías y clasificación de memes como Heylighen (1996), Dawkins (1976, 1989), Blackmore (1999), Benítez (2001), Aunger (2000, 2004), Benitez, L. (2001), Lissack,M.R. (2004), Berger, P. L. y Luckmann, T. (2006), Costaguta y Maldonado (2006), Knobel and Lankshear (2007), Wilson, E. O. (1998), Shifman y Thelwall, (2009), Shifman (2011), Skewes (2011), SkeweS, J. C. (2011), García, F. y Manuel Gertrudix, M. (2011), Aznavu- rian (2012), Naughton's (2012), McGrath, A. (2013), Shifman (2014), García Huerta, D. (2014), Arango, L. (2015), Dynel (2016), Laineste and Voolaid (2016), Yoon (2016), Pérez Salazar (2017), Yus, F., (2018).

2. Estudios específicos que analizan los memes en relación al humor, la ironía y sus contenidos Miltner (2014), Knobel y Lankshear (2007), Burguess, J. (2008).

3. Estudios que analizan el comportamiento de memes de acuerdo a sus rasgos fundamentales y efectos de viralización mediante modelos computacionales aplicados en redes sociales como Leskovec, Adamic y Huberman (2007), Weng , L., Flammini, A., Vespignani, A, Menczer, F. (2012), Taecharungroj, V., Pitchganut N. (2014), Da Cunha, R. (2007), Coscia, M. (2013, 2014), Kim, Y., Park, S., Yook, S. (2016), Qiu, X.,Oliveira, D., Sahami, A., Flammini, A., Menczer, F. (2017), Eschler, J., Menking, A. (2018). 
Los memes son un constructo social y cultural, su primera definición es originada por Richard Dawkins, zoólogo y científico, que en su libro The Selfish Gene (1976) formula una hipótesis memética sobre la transmisión cultural.

Richard Dawkins (1976) expone la hipótesis memética de la transmisión cultural. "Propone la existencia de dos procesadores informativos distintos en los seres humanos: uno actúa a partir del genoma gracias a la replicación de genes a través de las generaciones y otro actúa a nivel cerebral, replicando la información cultural del individuo, la cual es recibida por enseñanza, imitación o simple asimilación" (Martínez, 2014).

Los memes transitan por las redes no siempre de manera intacta, sino que pasan por diversos procesos de reinterpretación y modificación, lo que permite observar diversas versiones de un mismo meme, respetando o no la idea original, lo que permite su expansión viral (Knobel y Lankshear, 2007; en Pérez, 2014).

Hay memes convergentes que migran viralmente y no vuelven a aparecer, otros que se van resignificando con el tiempo y que se usan o reaparecen en momentos socioculturales específicos, los memes están sujetos a una temporalidad cultural y comparten una trama intertextual, se retroalimentan o comparten universos narrativos. Como apunta Coscia (2013): "Se dan ejemplos de memes muy populares que se extinguen al poco tiempo, mientras que otros, sin alcanzar el mismo nivel de rápido reconocimiento, sobreviven gracias a su asociación con otros memes".

Es fundamental subrayar la naturaleza transmediática del meme, engarzada a la convergencia de medios en donde los consumidores tienen una capacidad activa como comunidades de conocimiento y donde la narrativa se expande y se nutre de la trama sociocultural que emerge de los usuarios de las redes y plataformas digitales. Los memes se expanden narrativamente utilizando cualquier recurso de expresión textual, sonoro o visual, con características hipermediáticas Scolari (2013) y transmediáticas, entendidas como es el arte de crear mundos (Jenkins, 2008).

El meme se expande por diversas plataformas digitales como Instagram, Facebook, Twitter, WhatsApp y sitios web diseñadas para la comunicación en red y orientadas a promover comunidades participativas en manos de prosumidores (Toffler, 1970).

De esta forma, el comportamiento transmedia e hipermedia de los memes se expande de manera multiplataforma-participativa y en el presente estudio se observa que las narrativas y expresiones de los memes pueden migrar íntegramente de una plataforma a otra o bien expandirse narrativamente o presentar contenidos disímiles, dependiendo del contexto y coyuntura temática en cada plataforma o red social.

\section{Metodología}

El enfoque cualitativo que se aplicó en este estudio parte de una base etnográfica digital, con perspectiva sociocultural, se centró fundamentalmente en el estudio de casos y trabajo de campo etnográfico, en plataformas digitales y redes sociales cercanas a las comunidades digitales de siete profesores-investigadores del área de Humanidades y Comunicación pertenecientes 
al Tecnológico de Monterrey, involucrados en la recuperación de datos empíricos guiados por el objetivo principal de la investigación, como se ha indicado, investigar la construcción de imaginarios sociales construidos en torno a la identidad cultural mexicana en el contexto de la Copa del Mundo FIFA-2018.

La metodología cualitativa con enfoque etnográfico digital (Hine, 2005, 2007; Wouters y Beaulieu, 2009, Ardèvol y Gómez, 2012), se aplicó en este estudio debido a la experiencia propia de los investigadores experimentados en investigación en medios digitales y comunicación, y dado que se trata de una exploración cualitativa que no pretende hacer una radiografía de lo que sucede en las grandes redes de comunicación, las bases de datos masivas (big data) o a través de la computación distribuida (Ardèvol y Gómez, 2012), sino un análisis de los imaginarios sociales que construyen la identidad cultural mexicana, en el entorno de comunidades digitales cercanas a los investigadores participantes.

El enfoque etnográfico digital es entendido aquí como un método interdisciplinar (Guber, 2001) que enfocamos desde la perspectiva sociocultural que permiten dotar de sentido a una colectividad, en este caso mediante representaciones del imaginario social de la identidad mexicana. Las redes sociales y plataformas exploradas, a través de las comunidades cercanas de los investigadores, fueron Facebook, Instagram, Twitter, WhatsApp y Sitios web informativos (Cnn Expansión, El Universal, El Sol de México, Milenio, Uno Cero, Sopitas, Futbol Total, Hufftington Post y Sin Embargo). Los Sitios web informativos fueron elegidos porque se caracterizan por agregar memes con criterios de actualidad informativa, recuperados de redes, plataformas y sitios web.

La búsqueda para cada plataforma se realizó mediante recursos diversos, adaptados a cada una de ellas por sus cualidades de acceso. Para los Sitios Web informativos se realizó mediante el buscador de los propios portales; para Twitter e Instagram se hicieron mediante el buscador de la red social mediante la hashtag "selección mexicana", "México - Mundial 2018"; para Facebook se hizo posteando una solicitud de imágenes relacionadas con el tema a partir de los perfiles de los propios investigadores y en perfiles públicos relacionados con el tema central. De igual forma, para WhatsApp se exploraron y solicitaron memes relacionados con el tema de manera individual y en grupos ya constituidos en esta plataforma, a partir de comunidades pre-establecidas de los investigadores.

El corte de tiempo de la búsqueda que se realizó se acotó del 4 al 27 de junio de 2018. Esta temporalidad permitió encontrar expresiones visuales antes del partido de México contra Alemania, primer partido de la Selección Mexicana en la CMFR-2018, en el que resultó ganador, el día 17 de junio, y hasta el último partido en donde el equipo mexicano quedó descalificado de la competencia.

La búsqueda de imágenes se realizó de esta forma en tres momentos, antes del primer partido de la selección mexicana, en el que se observó un cambio en las narrativas visuales entorno a México en la CMFR-2018, durante los partidos que jugó la selección y hasta el 27 de junio, día en el que la Selección Mexicana se enfrentó contra la Selección de Suecia, perdió el encuentro y fue descalificada de la CMFR-2018. 


\subsection{Muestra}

Recordamos que este estudio tiene un enfoque cualitativo y sociocultural, por lo que no analizaremos cuantitativamente la muestra. Sin embargo, consideramos necesario, como parte de la metodología, dar cuenta del número de memes que componen la muestra cualitativa recolectada, ya que son la base a partir de la cual realizamos el análisis de imaginarios sociales y valores socioculturales de los memes.

La muestra total en todas las plataformas y redes sociales fue de 599 memes y la muestra final filtrada por los criterios de relevancia significativa, analizada para una lectura cercana (Moretti, 2007) fue de 69 memes.

Una vez recolectadas las expresiones visuales, se hizo una selección de memes aplicando los siguientes criterios de selección de las imágenes analizadas del total de expresiones narrativas de todas las plataformas:

1. Categorías temático-narrativas: las imágenes se clasificaron en seis categorías temático-narrativas para cada plataforma, estas categorías son parte importante de los hallazgos de esta investigación: Sexismo, Política y Elecciones, Religión, Personajes Populares, Cultura Mediática, Racismo.

2. Relevancia significativa: entendida como el valor de una imagen por su contenido significativo, frecuencia, multiplataforma, cruce narrativo.

El valor de relevancia significativo, que se define aquí por los valores culturales y mediáticos contenidos y expresados en los memes, dan como resultado las categorías temáticas que se observaron: Sexismo, Política y Elecciones, Religión, Personajes, Cultura Mediática, Racismo. Esta relevancia significativa se encontró como un valor inscrito en el contexto histórico del evento deportivo y en su temporalidad.

La metodología de análisis de los memes filtrados para su lectura cercana consistió en aplicar un protocolo que identifica los siguientes elementos: plataforma o red social, categoría temática, valoración (positiva, negativa), cruce narrativo, multiplataforma.

\section{Análisis de resultados}

El análisis de resultados está articulado en dos secciones: a) la primera a partir de las categorías temáticas encontradas y b) la segunda a partir de lo publicado en cada plataforma o red social. Incluiremos dos ejemplos de cada categoría por razones de espacio en este texto, pero dejamos la muestra completa en el siguiente enlace para su libre consulta: https://bit.ly/2Tmav4g

\section{a) Categorías y valores temáticos en memes}

Todas las plataformas y redes sociales analizadas presentaron memes con expresiones relacionadas con las siguientes categorías temáticas relacionadas con cada una de las seis categorías mencionadas anteriormente. La muestra total de memes analizados con una lectura cercana es como hemos indicado de 69, con la siguiente composición: 13 sexismo, 11 política y elecciones, 9 religión, 11 personajes populares, 11 cultura mediática, 14 racismo. 


\section{Sexismo}

El sexismo se presentó en memes publicados desde antes de la intervención de la selección mexicana de fútbol en la CMFR-2018, debido a una nota negativa que se publicó sobre una fiesta organizada por uno de los miembros de la selección y donde los jugadores aparecían fotografiados con un grupo de escorts.

A partir de ese momento y durante todo el período analizado se observan grados y tonos diversos de discriminación hacia la mujer y expresiones de tipo sexista relacionadas con los contrincantes de la selección mexicana. Valores discriminatorios que ofenden, insultan, humillan y tratan la figura de la mujer como objeto sexual, revelando un marcado machismo dispersado en diversas manifestaciones a través de los memes.
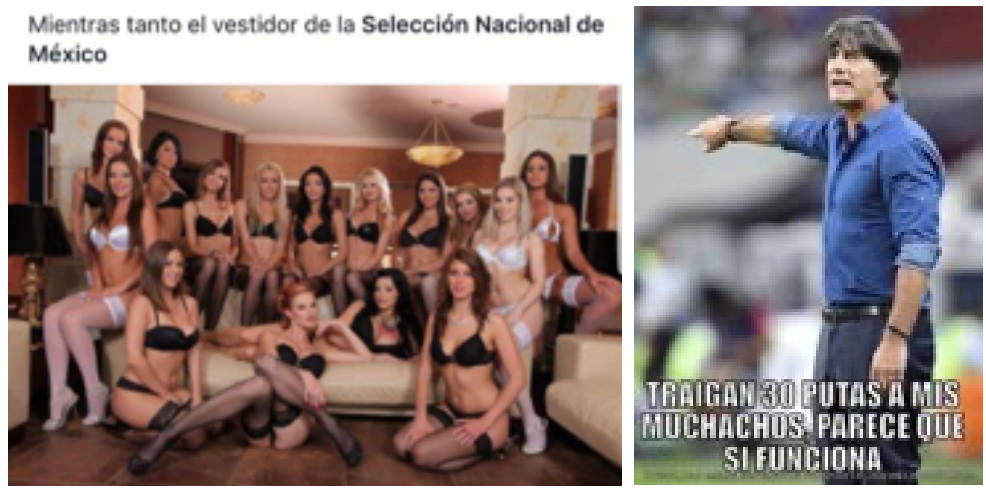

El meme sobre las escorts se refiere a la supuesta contratación de éstas por parte de la selección mexicana para una fiesta privada, previa al arranque de la CMFR-2018. El meme muestra claramente una objetivación y tratamiento sexista sobre la mujer y señala que están en el vestidor de la selección, subrayando implicaciones sexuales y expresando claramente un imaginario social sexista sobre la mujer.

El segundo meme muestra al director técnico de la selección alemana de fútbol, en donde el texto alude al meme anterior y señala la contratación de "30 putas" para los jugadores alemanes, dado que la selección mexicana ganó el encuentro con Alemania y se esperaba que la selección mexicana perdiera, el resultado final fue 1-0 a favor de México. En este meme también vemos un claro sexismo contra la mujer y un insulto, manifestando también valores propios del machismo de la cultura mexicana, construido claramente como imaginario social en los memes.

\section{Política y Elecciones}

En junio de 2018 se vivía en México el preámbulo de un proceso electoral histórico y que se desarrollaba de manera simultánea a la CMFR-2018. El tema electoral nacional fue protagonista de gran número de memes donde políticos como el ahora expresidente Enrique Peña Nieto y el ahora presidente, candidato entonces, Andrés Manuel López Obrador fueron protagonistas.

Al mismo tiempo, políticos de otros países como Angela Merkel, primera ministra de Alemania, y Kim Jong-un líder político de Corea del Norte, fueron también protagonistas, dado que la 
selección mexicana se enfrentó con la selección alemana y con la de Corea del Sur, citando a Kim Jong-un por asociación al país vecino.
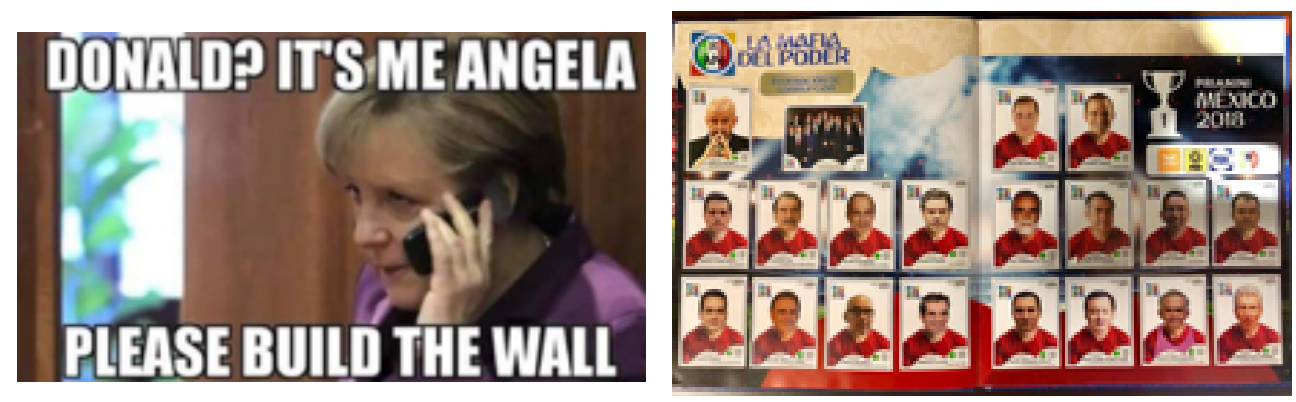

Es claro observar que la ironía está presente en los memes con temática política. En el de Angela Merkel se alude a la construcción del muro en la frontera con Estados Unidos proclamada por Trump, dado que la selección mexicana ganó a la selección alemana. Tiene un sentido negativo por la alusión al muro, y en tono irónico implica que los mexicanos no son deseables ni en Estados Unidos ni en Alemania.

En el meme "La mafia del poder" vemos también un tema político tratado con ironía y sentido negativo al representar a una "selección" conformada por políticos mexicanos, funcionarios y expresidentes, en donde el director técnico es Carlos Salinas de Gortari, expresidente de México. "La mafia del poder" hace alusión también a un slogan o concepto esgrimido por el candidato en la oposición en ese momento en plena campaña electoral, Andrés Manuel López Obrador, quien finalmente ganó la presidencia de México. Vemos una fuerte crítica a una clase política caracterizada por su ineficacia en la gubernatura del país, con un tratamiento irónico plasmado en el álbum de estampas Panini, en el contexto de la CMFR-2018.

\section{Religión}

La religión fue un tema recurrente en los memes publicados en el contexto de la CMFR-2018. Se observan alusiones a santos inscritos en la religión católica y fuertemente arraigados en la cultura mexicana, como San Judas Tadeo, figura que aparece en diversas versiones de memes combinadas con personajes populares.

El tratamiento en los memes con contenido religioso es identificable con algunos de los símbolos más representativos de las religiosidad mexicana. Se usan estos símbolos para exaltar aspectos positivos de la cultura popular, en este caso relacionados con jugadores o con la misma selección de fútbol.

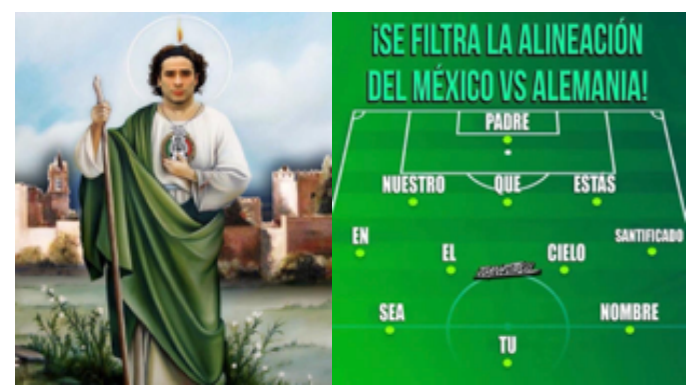


En el primer meme vemos el rostro del portero de la selección mexicana Guillermo Ochoa, quien tuvo un papel muy relevante en los juegos de la selección durante la CMFR-2018. Se representa en el cuerpo de San Judas Tadeo, quien pertenece a los doce apóstoles discípulos de Cristo y es reconocido porque en oración a él se encomiendan causas imposibles. De esta forma, el portero Memo Ochoa se ve convertido en San Judas Tadeo, santo de las causas imposibles de la selección mexicana.

En el segundo meme vemos cómo "Se filtra" la alineación de la selección mexicana para el partido contra Alemania, en donde cada jugador es una palabra del Padre Nuestro, oración representativa de la religión católica. El sustrato católico se expresa así con toda claridad en el contexto de la actividad de la selección de fútbol en la CMFR-2018, expresión profunda y actualizada a través de los memes de valores culturales fuertemente arraigados en México.

\section{Personajes Populares}

La migración narrativa y multiplataforma se dio también a través de personajes que fueron recurrentes en las diversas redes sociales y sitios web. Una parte de las narrativas en los memes fueron centradas en personajes populares, sobre todo futbolistas como Javier "Chicharito" Hernández, el director técnico Juan Carlos Osorio, Guillermo Ochoa, portero de la escuadra mexicana o el exjugador de fútbol Luis Roberto Alves conocido como "Zague".

En la muestra analizada los valores que se expresaron sobre los personajes fueron positivos, resaltando las cualidades heroicas relacionadas con el patriotismo o con valores religiosos. En este apartado observamos una fuerte tendencia a expresar narrativas transmedia con memes con alta intertextualidad asociada a contenidos religiosos o de la cultura mediática.
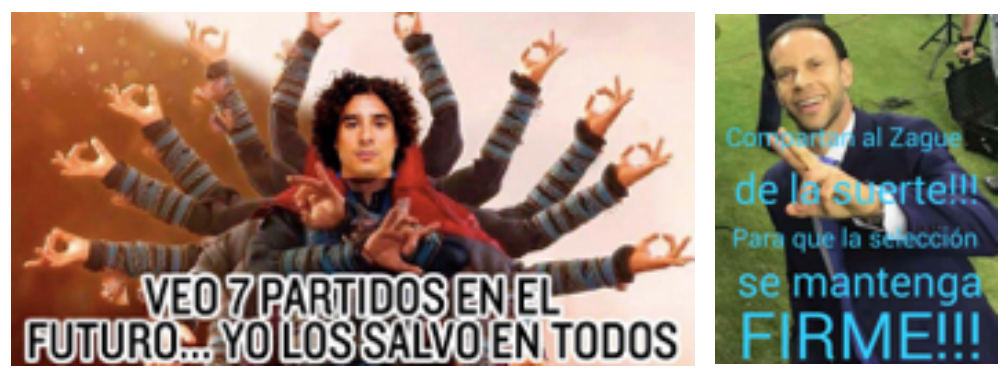

Nuevamente observamos la figura de Guillermo Ochoa, portero de la selección mexicana en numerosos memes donde se alude a películas como Matrix o en este caso a Doctor Strange, para representar poderes extraordinarios atribuidos al portero. Observamos una clara migración de contenidos de la cultura mediática centrados en un personaje y una expansión narrativa inscrita en el contexto de la CMFR-2018. Guillermo Ochoa fue el personaje más representado en memes junto con Javier "Chicharito" Hernández en nuestra muestra.

Observamos también un fenómeno transmedia en la representación del jugador Luis Roberto Alves conocido como Zague, exjugador de fútbol y presentador de la CMFR-2018 en un canal televisivo, fue protagonista de un escándalo al viralizarse en Twitter un video donde el exjugador aparece mostrando sus genitales. El escándalo migró y se expandió narrativamente en todas las plataformas analizadas, en sitios web y redes sociales. 
En el meme observamos al exjugador Zague en una clara alusión sexual y referida a la actuación de la selección mexicana en la CMFR-2018. Para entender el sentido de este meme es necesario comprender el contexto del video viralizado y el contexto de la selección durante la CMFR-2018. Zague se convirtió así en un personaje multiplataforma, transmediático e inscrito en una narrativa sexual articulada en la cultura sobre el fútbol en al marco de la CMFR-2018.

\section{Cultura Mediática}

En este apartado encontramos signos de transmedialidad y cultura mediática en memes que hacen alusión a series de televisión como la de Luis Miguel, films como Thor, o el personaje Thanos de la zaga de Avengers de Marvel, series de televisión como El Chapulin Colorado o Los Simpson. También se hacen alusiones a cultura popular mexicana como el juego de la lotería.
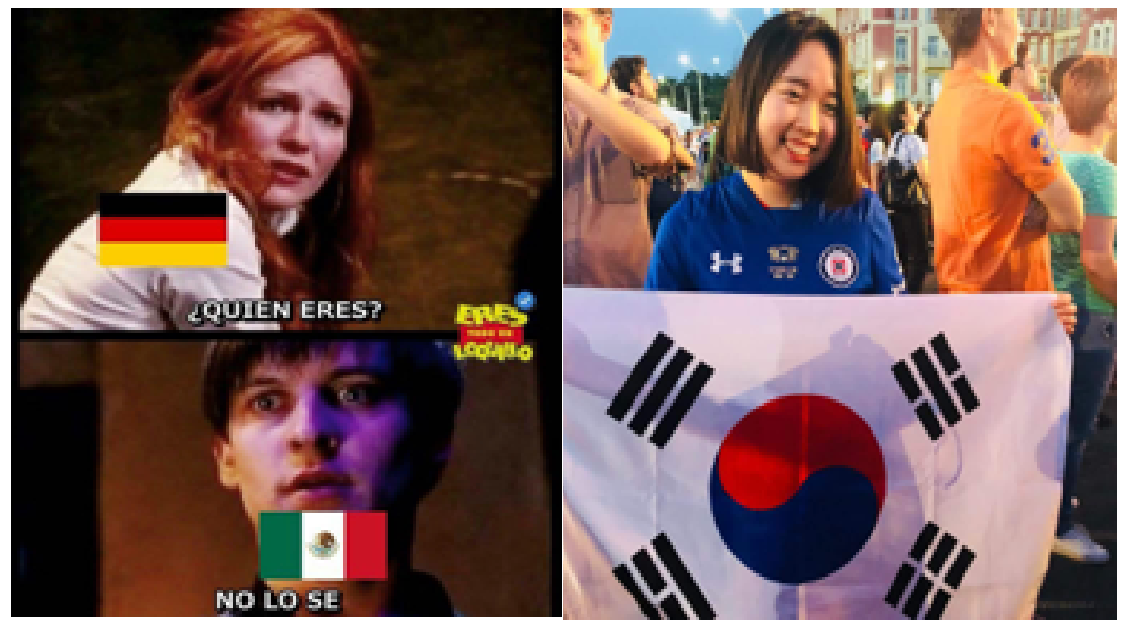

Destaca el meme que alude a la película de Spider-Man (2012) en donde con sentido irónico el personaje principal protagonizado por Tobey Maguire simbolizado con una bandera de México, sufre una crisis de identidad. El meme refiere al triunfo de la selección mexicana (1-0) sobre Alemania en la CMFR-2018, que resultó toda una sorpresa para los mexicanos, una actuación "irreconocible". La cultura mediática se emplea como cita intertextual para articular una expresión "positiva" de la actuación de la selección mexicana de fútbol.

El segundo meme fue igualmente viralizado en todas las plataformas estudiadas. En este caso una joven con rasgos orientales sostiene una bandera de Corea y viste una camiseta del equipo Cruz Azul, perteneciente a la liga de fútbol mexicana. El meme es irónico ya que el equipo Cruz Azul mantiene una larga racha sin ganar un campeonato de liga. El hecho de que una joven con rasgos orientales porte la camiseta del Cruz Azul implica, en la cultura futbolística mexicana, un signo de "mala suerte" y la posibilidad de que Corea perdiera frente a México en el partido que llevaron cabo en el contexto de la CMFR-2018.

Se trata de una compleja combinación de símbolos que sólo se pueden comprender dentro del contexto propio de la cultura futbolística mexicana y en relación a la actuación de la selección de fútbol mexicana en la CMFR-2018, en este caso, una joven que involuntariamente se convirtió en un personaje portadora de símbolos mediáticos populares. 


\section{Racismo}

El racismo fue una constante en los memes publicados en las diversas redes sociales, plataformas y sitios web. Expresado principalmente a través de la señalización de rasgos físicos en personas o animales, relacionados con los equipos de fútbol contra los cuales se enfrentó la selección mexicana, principalmente Alemania y Corea. Sin embargo, también se expresaron memes con manifestaciones de auto-discriminación racista, propios de la cultura mexicana.

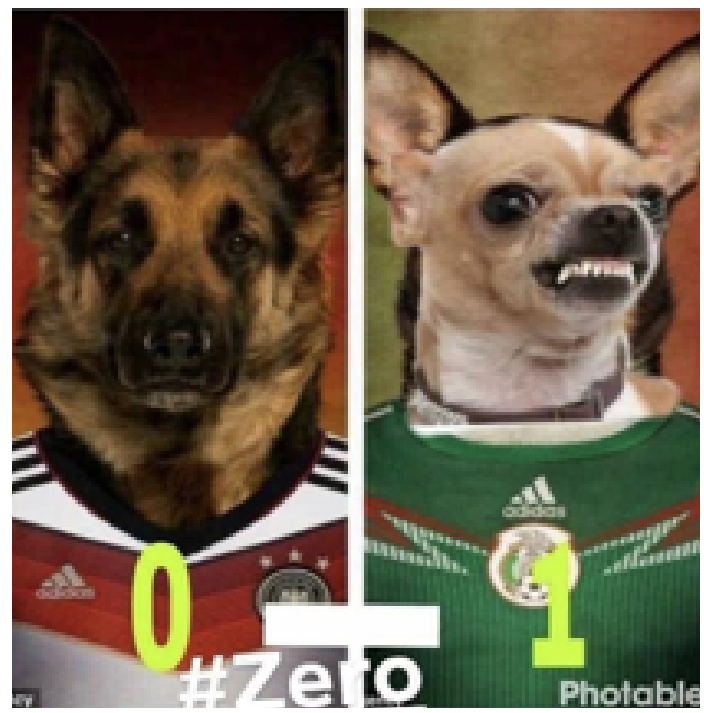

\section{No sé a quién irle si a México o a mi Alemania}

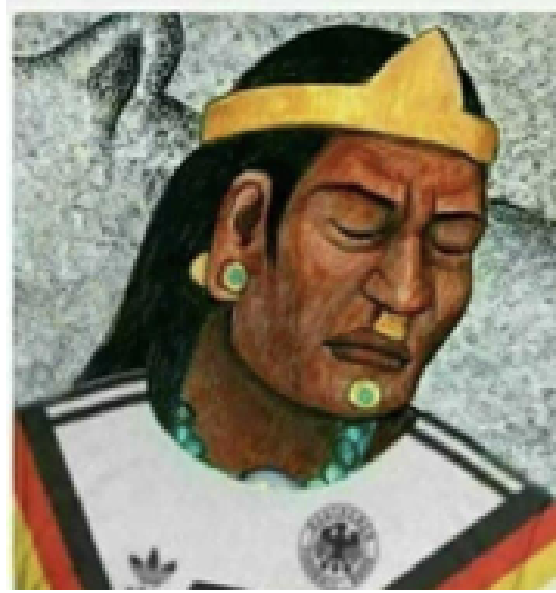

Los rasgos físicos de los perros Pastor Alemán para Alemania y Chihuahua para México, representan en este meme de manera irónica, racista y negativa el triunfo de la selección mexicana sobre la escuadra alemana. La auto-discriminación aparece aquí al representar a México con un perro Chihuahua frente a un Pastor Alemán visiblemente más grande y fuerte.

En el segundo meme observamos una "herencia" del mito de la Malinche, quien sirvió al conquistador español Hernán Cortés a establecer traducción y contacto con la cultura indígena mexicana en tiempos de la conquista de España sobre México. Ser "malinchista" en la cultura mexicana, es preferir al extranjero sobre lo nacional. En el meme vemos la representación de un hombre con rasgos indígenas mexicanos vestido con la camiseta de la selección alemana de fútbol y en la leyenda se reafirma esta forma de dualidad identitaria, al dudar a qué equipo apoyar, subrayando con la expresión "No se a quien irle si a México o a mi Alemania" implica una forma de auto-discriminación.

\section{b) Plataformas, redes sociales y sitios web}

El comportamiento de los prosumidores (Toffler, 1970) que publicaron memes en las diversas plataformas, redes sociales y sitios web, aunque con características similares, no se expresó de la misma manera. Cada una de las plataformas, redes sociales y sitios web mostró diferencias en el número de memes publicados, diversidad de contenidos y sobre todo márgenes distintos de "apertura moral" (atrevimiento o margen moral), que podemos traducir como grados de violencia mayores en las expresiones sobre las categorías temáticas encontradas, especialmente en los temas de sexismo y racismo. 
De esta forma la plataforma más abierta a la publicación de mayor número de memes y con mayor carga de violencia en temas sobre sexismo y racismo fue WhatsApp. Esto debido a que las publicaciones se comparten de manera privada entre pares o en un grupo cerrado de personas conocidas. La apertura moral o el grado de violencia depende en este estudio del grado de exposición pública de la plataforma o red social.

Facebook se caracterizó por ser la red social con el mayor número de memes publicados y un grado menor de violencia en las expresiones sobre las diversas categorías temáticas. Contrasta con Instagram que fue la red con menor cantidad de memes publicados después de Twitter. Los Sitios web informativos se caracterizaron por hacer colecciones de memes y reunir por criterios de actualidad los memes más viralizados en las redes.

En general, exceptuando WhatsApp por las características arriba descritas, Facebook, Instagram, Twitter y los sitios web de información, comparten las mismas características de memes publicados, con las mismas categorías temáticas, grados positivos y negativos expresados de manera similar, variando únicamente en la cantidad de memes publicados.

Es importante subrayar que el comportamiento cualitativo en las diversas plataformas y valores de relevancia significativa, tanto en redes sociales y Sitios web de información es similar, aunque notablemente diferenciado con WhatsApp por las razones ya explicadas.

La dispersión de memes en las diversas plataformas, redes sociales y sitios web de información es similar, aunque cabe señalar que no todos los memes se publicaron en todas las plataformas, redes sociales y sitios web informativos.

Algunos memes, como los analizados en la selección ya filtrada usada en este estudio, migraron en todas las plataformas, redes sociales y sitios web informativos. Lo que nos permitiría teorizar sobre la posibilidad de definir características de memes de mayor influencia, o posibilidad de viralización multiplataforma y transmedia, de acuerdo a sus características de contenido, tratamiento simbólico, valores culturales, convergencia y construcción estética. Lo anterior nos permitiría pensar en la existencia de "protomemes" que reúnan características culturales extendidas y convergentes con el contexto específico de su viralización.

\section{Discusión y conclusiones}

El análisis de la construcción de la identidad mexicana a través de los memes publicados en el contexto de la CMFR-2018, revela con claridad los tópicos, estereotipos, apertura moral, ética, la simbología popular, mediática, estética y los valores que conforman el imaginario social sobre temas arraigados e instituidos en la cultura mexicana, en su historia y que afloran actualizados en redes sociales y plataformas digitales.

De esta forma, el análisis permitió encontrar los siguientes hallazgos:

1. Los memes analizados son una expresión de imaginarios sociales instituidos en la identidad cultural mexicana, dados los valores socioculturales que exponen: Sexismo, Religión, Personajes Populares, Racismo, expresión actualizada y contemporánea de lo estudiado por Ramos (1951) y Paz (1992), sumándose la Cultura Mediática, y Política y Elecciones a este universo sociocultural. 
2. Las categorías temáticas encontradas en la producción de memes, Sexismo, Política y Elecciones, Religión, Personajes Populares, Cultura Mediática, Racismo se construyen a partir de los imaginarios sociales instituidos culturalmente en la sociedad mexicana, son dinámicos en el tiempo, operan y construyen una realidad social y mediática

3. Los memes construyen universos simbólicos que contribuyen a la construcción de una identidad individual y colectiva, una identidad social dinámica compartida social y culturalmente.

4. Los memes analizados son imaginarios sociales alimentados por la cultura futbolística popular mexicana, un "sistema de representación de realidad" como apunta Villoro (2018)

5. Encontramos claros rasgos de transmedialidad narrativa multiplataforma, extraída de elementos y valores de la cultura popular, tradiciones y cultura mediática, insertas en un contexto específico como forma de actualización con ejes narrativos específicos, basados principalmente en películas de ficción y superhéroes

6. Los memes son producidos y publicados por parte de ciudadanos y de autoría anónima. Se trata de una práctica de apropiación de contenidos y apropiacionismo realizada por prosumidores en redes sociales y plataformas digitales

7. La totalidad de los memes analizados muestran rasgos de humor e ironía, ya sea en sentido negativo, violento, discriminatorio, exaltativo o positivo. La ironía es un componente esencial de los memes y el humor funciona como catalizador de frustraciones, válvula de escape de resentimientos o violencia contenida

8. El comportamiento de los prosumidores no es el mismo en las diversas redes sociales y plataformas digitales, siendo WhatsApp la plataforma de mayor apertura moral y mayor grado de violencia en las expresiones publicadas mediante memes

9. Se identificó la presencia de memes que, sin seguir una fórmula, se caracterizan por reunir valores, temática, cruces narrativos y elementos simbólicos culturales integrados de tal forma que tuvieron presencia en diversas plataformas, redes sociales y sitios web informativos, por lo cual podemos denominarlos "protomemes"

La identidad cultural mexicana se construye cada día, las redes sociales y plataformas digitales son un espacio sociocultural de construcción altamente usado por la sociedad mexicana.

Los memes son un instrumento en la construcción de la identidad, una forma de articulación del descontento la conformidad colectiva, un arma política y una forma de canalizar frustraciones, violencia contenida, crítica social, autocrítica y, en suma, son una expresión, reflejo o construcción de imaginarios sociales de la identidad cultural mexicana mediante el humor y la ironía, no exentos de violencia, transgresión, insultos o por el contrario mediante pactos discursivos consensuados éticamente (o no), compartidos en momentos coyunturales, eventuales, estratégicos o por divertimento social.

\section{Referencias}

- Arango, L. (2015). Una aproximación al fenómeno de los memes en Internet: claves para su comprensión y su posible integración pedagógica. Comun, Mídia Consumo. doi: 10.18568/1983-7070.1233109-131.

- Ardèvol, E., y Gómez, E. (2012). Las tecnologías digitales en el proceso de investigación social: reflexiones teóricas y metodológicas desde la etnografía virtual. Barcelona: CIDOB.

- $\quad$ Aunger, R. (2004). El meme eléctrico. Barcelona: Paidós. 
- $\quad$ Aunger, R. (2000). The status of memetics as a science. Nueva York: Oxford University Press.

- Bañuelos, J. (2008). Fotomontaje. Madrid: Cátedra.

- $\quad$ Benitez, L. (2001). Memetics: a dangerous idea. Interciencia, (vol. 26, núm. 1, enero, 2001, pp. 29-31). Recuperado de https://bit.ly/2VbHsyh

- $\quad$ Berger, P. L. y Luckmann, T. (2006). La construcción social de la realidad. Buenos Aires: Amorrortu.

- $\quad$ Castoriadis C. (1975). La institución imaginaria de la sociedad II. Buenos Aires: Tusquets.

- Castoriadis, C. (1997). El imaginario social Instituyente. Recuperado de https://bit.ly/1Gze$\underline{\text { GJI }}$

- Burguess, J. (2008). All your chocolate rain are belong to us? Viral video, YouTube and the dynamics of participatory culture. En Lovink, G. y Niederer, S. (eds.) Video Vortex Reader: responses to YouTube. (pp. 101 -109). Amsterdam: Institute of Network Culture.

- Blackmore, S. (1999). The meme machine. New York: Oxford University Press.

- Coscia, M. (2013). Competition and Success in the Meme Pool: a Case Study on Quickmeme.com. Cambridge:

- $\quad$ CID - Harvard Kennedy School. Recuperado de https://arxiv.org/abs/1304.1712

- Coscia, M. (2014). Average is Boring: How Similarity Kills a Meme's Success. Scientific Reports. CID - Harvard University. doi: https://doi.org/10,1038/srep06477

- Costaguta, R., y Maldonado, M. (2006). JISTEM J.Inf.Syst. Technol. Manag. (Online) [online]. 2006, vol.3, n.1, pp.53-66. ISSN 1807-1775. doi: http://dx.doi.org/10.1590/S180717752006000100005

- Da Cunha, R. (2007). Memes em weblogs: proposta de uma taxonomía. FAMECOS, 32, pp. 23 - 31. doi: http://dx.doi.org/10.15448/1980-3729.2007.32.3411

- Dawkins, R. (1989). The Selfish Gene (2. a edición). Oxford: Oxford University Press.

- Dawkins, R. (1976). The selfish gene. Oxford: Oxford Landmark Science.

- Dynel, M. (2016). 'I has seen image macros!' Advice animal memes as visual-verbal jokes. International Journal of Communication 10. International Journal of Communication 10(2016), Feature 660-688. Recuperado de https://bit.ly/2TRIHCc

- Eschler, J., y Menking, A. (2018). No Prejudice Here: Examining Social Identity Work in Starter Pack Memes. Social Media and Society. doi: https://doi.org/10.1177/2056305118768811

- García, F., y Gertrudix, M. (2011). Naturaleza y características de los servicios y los contenidos digitales abiertos. en CIC. Cuadernos de Información y Comunicación (vol. 16, pp. 125-138). Recuperado de https://bit.ly/2HQsHhf

- García Huerta, D. (2014). Las imágenes macro y los memes de internet: Posibilidades de estudio desde las teorías de la comunicación. En Paakat: Revista de tecnología y sociedad (Año 4, num. 6, marzo - agosto 2014). Recuperado de https://bit.ly/2Vc4UeK

- Giddens, A. (1997). Modernidad e identidad del yo. Barcelona: Península.

- Giménez, G. (2000). Materiales para una teoría de las identidades sociales. En Valenzuela, J. (coord.), Decadencia y auge de las identidades. México: El Colegio de la Frontera Norte y Plaza y Valdés.

- Guber, R. (2001). La etnografía: método, campo y reflexividad. Bogotá: Editorial Norma.

- Heyligher, F. (996). Evolution of Memes on the Network: from chain-letters to the global brain. En Fischer, I. (Ed.). Ars Electronica Catalogue. Vienna/New York: Springer.

- Jenkins, H. (2008). Convergence Culture. La cultura de la convergencia de los medios de comunicación. Barcelona: Paidós 
- Hine, C. (2005). Virtual methods: Issues in social research on the Internet. Oxford: Berg Publishers.

- Hine, C. (2004). Etnografía Virtual. Barcelona: Editorial UOC.

- Kim, Y., Park, S., Yook, S. (2016). The origin of the criticality in meme popularity distribution on complex networks. Scientific Report. doi: 10,1038/srep23484

- Knobel, M., y Lankshear, C. (2007). Online memes, affinities, and cultural production. En A New Literacies Sampler, Publisher: Peter Lang, Editors: M. Knobel \& C. Lankshear, pp.199227. Recuperado de https://bit.ly/2HRQuNS

- Knobel, M., Bigum, C. y Peters, M. (Eds.), A new literacies sampler (pp. 199 - 228). Nueva York: Peter Lang.

- $\quad$ Laineste, L. y Piret, V. (2016). Laughing across borders: Intertextuality of internet memes. European Journal of Humour Research $(4,4)$ pp. 26-49). doi: http://dx.doi.org/10.7592/ EJHR2016.4,4.laineste

- Leskovec, J., Adamic, L. A., y Huberman, B. A. (2007). The dynamics of viral marketing. ACM Transactions on the Web, 1 (1). doi: http://dx.doi.org/10.7592/EJHR2016.4.4.laineste

- Lissack, M.R. (2004). The Redefinitionof Memes: Ascribing Meaningtoan Empty Cliché. Journal of Memetics - Evolutionary Models of Information Transmission, 8. doi: https://doi. org/10.1207/s15327000em0503 6

- McGrath, A. (2013). Dawkin's God. Genes, memes and the meaning of life. Nueva Jersey: John Wiley \& Sons.

- Magallón, M. (2007). Samuel Ramos y su idea de cultura en México. México: CCyDel/ UNAM. Recuperado de https://bit.ly/2Vl8oLF

- Mandoki, K. (2006). Prácticas estéticas e identidades sociales. México: Conaculta.

- Martínez, R. (8 de julio de 2014). El significado cultural del meme se propaga con el relajo cibernético. La Jornada, Cultura. Recuperado de https://bit.ly/2PrJYwH

- Miranda, A. (2014). El imaginario social bajo la perspectiva de Cornelius Castoriadis y su proyeccion en las representaciones culturales de Ccartagena de Indias. Cartagena de Indias: Universidad de Cartagena-Facultad de Ciencias Humanas.

- Miltner, K. M. (2014). There's no place for lulz on LOLCats': The role of genre, gender, and group identity in the interpretation and enjoyment of an Internet meme. First Monday. doi: https://doi.org/10.5210/fm.v19i8.5391

- Moretti, F. (2007). La literatura vista desde lejos. Barcelona: Marbot.

- Naughton, J. (2012). From Gutenberg to Zuckerberg: What You Really Need to Know about the Internet, London: Quercus.

- $\quad$ Paz, O. (1992). El laberinto de la soledad. México: Fondo de Cultura Económica.

- Pérez Salazar, G., Aguilar, A. y Guillermo, M. (2014). El meme en internet. Usos sociales, reinterpretación y significados, a partir de Harlem Shake. Argumentos [online] 27. Recuperado de https://bit.ly/2XoLrcd

- Pérez Salazar, G. (2017). El meme en Internet. Identidad y usos sociales. México: Fontamara / Universidad Autónoma de Coahuila.

- Qiu, X.,Oliveira, D., Sahami, A., Flammini, A., y Menczer, F. (2017). Limited individual attention and online virality of low-quality information. Nature Human Behaviour (volume 3, p. 102). doi: https://doi.org/10,1038/s41562-017-0132

- Ramos, S. (1951). El perfil del hombre y la cultura en México. México: Austral.

- Scolari, C. (2013). Narrativas transmedia: cuando todos los medios cuentan. Barcelona: Deusto. 
- $\quad$ Shifman, L. (2011). An anatomy of a YouTube meme. En New Media \& Society. (14 (2), 187202). doi: https://doi.org/10.1177/1461444811412160

- Shifman, L., y Thelwall, M. (2009). Assessing global diffusion with Web Memetics: The spread and evolution of a popular joke. Journal of the American Society for Information Science and Technology. (60/12), pp. 2567-2576). doi: https://doi.org/10.1002/asi.21185

- Skewes, J. C. (2011). De la selección natural a la cooptación social de la genética: El tránsito de Carlos Darwin por la cultura. Polis, Revista de la Universidad Bolivariana. (10-28). doi:http://dx.doi.org/10.4067/S0718-65682011000100025

- Taecharungroj, V., y Pitchganut, N. (2014). The effect of humour on virality: The study of Internet memes on social media. Paper presented at 7th International Forum on Public Relations and Advertising Media Impacts on Culture and Social Communication. Bangkok, August. doi: http://dx.doi.org/10,17011/ht/urn.201511113638

- Toffler, A. (1970). Future Shock. United Satates of America: Random House.

- Vázquez, F. (2001). La memoria como acción social. Relaciones significados e imaginario. Barcelona: Paidós.

- Vesga, N. (2016). Memes: una expresión que se valida desde la imagen y el humor. Colombia: Universidad Autónoma de Bucaramanga. Recuperado de https://bit.ly/2BnPqfU

- Villoro, J. (2018). Conferencia "Futbol e identidad social". UNAM: Auditorio Ricardo Flores Magón de la Facultad de Ciencias Políticas y Sociales. Boletín UNAM-DGCS-72. Recuperado de https://bit.ly/2CHQFIm

- Weng , L., Flammini, A., Vespignani, A, y Menczer, F. (2012). Competition among memes in a world with limited attention. Scientific Report. doi: 10.1038/srep02304

- Wilson, E. O. (1998). Consilience: The Unity of Knowledge. Nueva York: Alfred A. Knopf, Inc.

- Wolton, D. (1999). Sobre la Comunicación. Madrid: Acento.

- Wouters, P. y Beaulieu, A (2006.). Imagining e-science beyond computation. En: Hine,Ch. (ed.). New Infrastructures for Knowledge Production: Understanding E-Science. Hershey, PA: Information Science Publishing.

- Yoon, I. (2016). Why is it not Just a joke? Analysis of Internet memes associated with racism and hidden ideology of colorblindness. Journal of Cultural Research in Art Education 33. Recuperado de https://bit.ly/2Uikmd2

- Yus, F., (2018). Identity-related issues in meme communication. Internet Pragmatic, pp. 113-133. issn 2542-3851 | e-issn 2542-386x @ John Benjamins Publishing Company's. doi: https://doi.org/10.1075/ip.00006.yus

\section{Agradecimientos}

Agradecemos al Dr. Edgar Gómez Cruz, profesor en la School of Arts and Media de la University of New South Wales, Sidney, Australia, por su apoyo y orientación. Agradecemos igualmente a los profesores que contribuyeron en la búsqueda de memes, dentro del Taller sobre Investigación Cualitativa, impartido por el Dr. Gómez Cruz en el Tecnológico de Monterrey en 2018: Rodolfo Langer López, Judith Cortés Váquez, Armando Ruiz Rojas, David Kenji Calderón, Rudi Langner. 